parts is only about to in. per annum. The valley possesses considerable mineral wealth, including gold, copper, lead, iron, turquoise, coal, and gypsum. The metalliferous deposits, especially gold, have been extensively worked. But, from an agricultural point of view, the district has been practically neglected. Vast tracts of arable land, capable of producing valuable crops, lie uncultivated for lack of treatment. In any system of development, artificial irrigation would, of course, be a necessity, but there are abundant stores of underground water available for exploitation and use. As in south-eastern Nevada, these supplies are more prolific in the "valley-fill" than in the "bedrock." The most important sources are the sand and gravel deposits, which lie in irregular lenticular masses at different depths in different localities. The Cretaceous rocks, however, underlying the eastern portion of the basin, yield a sufficient supply for domestic and cattle-raising purposes.

Further to the west lies the great State of California, second only to Texas in point of size, and characterised by a remarkable physiographical diversity. Thus it encloses both the highest and the lowest levels in the Union, viz., $14,501 \mathrm{ft}$. above the sea (Mount Whitney), and $276 \mathrm{ft}$. below the same datum (Death Valley). There are equally diverse hydrographic features. In the southern deserts is to be found the extreme of aridity: a rainfall which averages less than 3 in. per annum, and, in some years, is merely a trace; whereas, in the north-west, there is very heavy precipitation, amounting to an annual average of close on 100 in. at certain stations. Mr. Waring's paper contains a very full account of the natural springs scattered throughout the State, with an interesting study of their occurrence and yield. The hot springs are perhaps the most remarkable class, and these include all springs having a temperature higher than about $90^{\circ} \mathrm{F}$. Other groups of springs include carbonated springs, sulphur springs, saline springs, magnesic springs, and iron springs, each class named after the constituent which marks the flavour and character of the water. One curious spring is the socalled "poison spring" on the western border of Death Valley, which is an arm of the Colorado Desert. It yields a salty water, impregnated probably with sulphates, producing a strong feeling of nausea in anyone imbibing it. Other popularly described "poison" springs are believed to contain arsenic, but of this there is some doubt, as arsenic is a rare constituent of water and seldom present in measurable amount.

The most prominent topographical feature of California is the Great Central Valley, 16,000 square miles in area, flanked on each side by mountain ranges running parallel with the coast. One portion of this is the Sacramento Valley, a broad and fertile plain lying between the Sierra Nevada and the Coast Range. It is a district unmistakably adapted to agricultural pursuits, possessing climatic conditions of the most favourable kind. The winters are moderate, and the rainfall, which averages from 20 to 25 in. annually, is concentrated, in a large measure, within the five months of their duration. The orchard industry has acquired special prominence. All deciduous fruits bear heavy crops, being rarely damaged by frost, while the more delicate varieties, such as apricots, almonds, olives, etc., flourish in suitable localities. Under normal conditions it is quite unnecessary to resort to artificial irrigation, but, as a means to the more extended and intensive cultivation of ground crops and the inclusion under operation of certain lands at present only available for grazing, the study of water storage and distribution is receiving attention. The ground water is principally contained in the uppermost alluvial deposits, and the valley is remarkable NO. $24 \pi 8$, VOL. 977 for the large area in which the water-level stands near the surface of the ground. The alluvium is of two periods: an older deposition dating from the Pliocene epoch and continuing into the Pleistocene, and a later deposit of more recent formation. This latter is the most productive water-bearing stratum, and consists largely of sands and gravels in an uncemented condition. The total quantity of ground water in the valley is undoubtedly very considerable, and the application of irrigation from this source presents great possibilities of development.

Adjacent to the Sacramento Valley, on the eastern side of San Francisco Bay, is situated a somewhat notable cone of alluvial deposit, built up by a neigh bouring creek, and called, from its proximity to a town of the name, Niles Cone. The cone proper is I 1,800 acres in extent, but a marsh tract adds 9000 acres to the area forming the ground-water district covered by Mr. Clark's report. The creek from which the cone derives its origin is Alameda Creek, at the outlet of the Santa Clara Valley. This receives the drainage of 640 square miles of mountains and interior valleys. The alluvial deposits have been brought down by streams during periods of irregular flow. The upper layers belong to the Pleistocene and Recent series of the Quaternary system; the lower strata form part of the Orinda formation in the Pliocene series. Below these fresh-water deposits lie shale and sandstone of the Cretaceous, and, possibly, of the Jurassic periods. The development of artificial irrigation is proceeding rapidly, and numerous wells have been sunk during the past few years, but the limit of yield from the ground water has almost been attained, and any further supplies will have to be obtained by conserving the large quantities of flood water which have hitherto been allowed to run to waste.

B. C.

\section{SOME RECENT STUDIES ON PROTOZOA AND DISEASE.}

R. J. W. SCOTT MACFIE describes in Annals of Tropical Medicine and Parasitology (vol. ix., No. 4) a number of interesting protozoa from Accra, West Africa. He records the occurrence of a piroplasm-Nuttallia decumani, n. sp.-in the blood of brown rats, and gives an account of a case of amcbic dysentery in a monkey (Cercopithecus), in which numerous Entamœba were present, together with a vast number of minute spirochætes. He designates as a new variety (var. equinum) a strain of Trypanosoma congoiense, chiefly on the ground that in many of the trypanosomes the trophonucleus lies near the anterior end. The clinical aspect of the disease produced by this.trypanosome in the original host-a mare-was also peculiar in that there appeared on the skin of the body raised disc-like patches or plaques, which, however, disappeared after about three days. Dr. Macfie also records observations on two mules suffering from a form of trypanosomiasis clinically resembling acute dourine, and states that in these cases infection by coitus-the usual method of transmission of this disease-may be excluded with certainty.

An account of researches by Drs. Fantham and Porter on induced herpetomoniasis in birds appears in the same number of the Annals. Water-scorpions and gnats, in the intestine of which the flagellate parasite Herpetomonas was present, were fed to birdscanaries, sparrows, and martins. A fatal infection of the birds ensued, and herpetomonads, flagellate and nonflagellate, were found in the internal organs (liver, spleen, bone-marrow, etc.). The disease ran either an acute or a chronic course. In acute cases the flagellate form of the parasite was more common in the birds at death, while in chronic cases the non- 
flagellate forms-often Leishmania-like-were more numerous. The authors recall the fact that a flagellate stage of Leishmania donovani-the causal organism of kala azar in man-has recently been found by Dr. Wenyon in a dog subinoculated with a strain derived from a human case, and that flagellate stages of $L$. tropica-the organism of oriental sorehave been found in man. In view of the similarity of the morphological cycles of Leishmania and Herpetomonas, the authors suggest that the species of Leishmania are probably insect herpetomonads introduced long ago into man, and usually perpetuating the non-flagellate and relatively non-resistant forms, though capabie of assuming the flagellate form.

\section{THE NEW ZEALAND INSTITUTE.}

THE forty-seventh volume of the Transactions and Proceedings of the New Zealand Institute constitutes a record of much valuable and painstaking research, dealing chiefly with the fauna and flora of the Dominion. It is gratifying to find that the war has interfered so little with the activities of New Zealand naturalists, and that so many ardent workers are now engaged in adding to our already very extensive knowledge of this important region. Most of the papers in this volume are of a systematic character, and probably work of this kind is the most important that can be undertaken at the present time in New Zealand. Such papers, however, naturally appeal to a very limited number of readers, especially when they are written in the ultra-technical language which so many systematists seem to prefer. This appears very markedly in Mr. Meyrick's revision of New Zealand Tineina, in which the diagnosis of the very first genus contains the following cryptic sentence-if sentence it can be called:-- "Hindwings under $I$, termen abruptly emarginate beneath acutely produced apex; 3 and 4 rather approximated, 5 nearly parallel, 6 and 7 rather approximated towards base."

We cannot help thinking that, apart altogether from the question of style, a somewhat more generous expenditure of type would be appreciated by those who might like to take up the study of this group of Lepidoptera in New Zealand, and are not already experts in the subject. Mr. Meyrick is of opinion that there still remain a large number of additional species of Tineina to be discovered in New Zealand, and it seems a pity, therefore, that the generic and family characters given only hold good for the New Zealand species, for apparently they may be upset at any time by further discoveries, and may prove quite inadequate for the determination of new forms.

One of the most interesting discoveries recorded in the volume is that of a new genus of gymnoblastic hydroids, Ascidioclava, found living as a parasite in the peripharyngeal groove of an Ascidian, and described by Prof. H. B. Kirk.

We are glad to see that local botanists are paying attention to the life-history of the Lycopodiaceæ, which form such an important element in the New Zealand flora. Mr. J. E. Holloway contributes a note on the protocorm of Lycopodium laterale, and Miss $\mathrm{K}$. V. Edgerley describes the prothallia of three species. Prof. Charles Chilton gives an interesting account of the recently established Mountain Biological Station belonging to the Canterbury College, the existence of which may be expected to do much to promote biological research.

It is impossible in a short notice to do justice to such a mass of valuable material as this volume contains. We can only express our satisfaction at the great activity displayed, and congratulate all concerned on the results of their labours.

A. D.

\section{THERAPEUTIC ACTION OF ULTRA-} VIOLET RAYS.

$A$ TTENTION has recently been directed again to the $\mathrm{A}$ therapeutic action of ultra-violet rays by the publication of a paper in the Lancet of January 8 , in which a source of light invented by Mr. Simpson was referred to. There is nothing novel, of course, in the fact that certain forms of disease may be cured by exposure to light of wave-length ranging from $300 \mu \mu$ to $90 \mu \mu$, but the discovery of a new ultra-violet lamp raises many questions of wide interest. Dr. Sidney Russ has now shown, however, that an arc simply produced between two tungsten rods exactly simulates the socalled "Simpson light," and it is evident that the powerful source of ultra-violet rays thus obtained will prove of service in the treatment of all those superficial lesions which Finsen and others have proved to be favourably affected by this type of radiation. Dr. Russ has further pointed out that even one-tenth of a millimetre of human skin readily absorbs a large part of the ultra-violet rays from this arc, and that less than one per cent. passes to a depth of one millimetre.

When its spectrum is compared with that of the mercury arc, the carbon arc, or one between copper and silver, it is seen to consist of numerous lines grading off towards the shortest wave-length, and affording an exceptionally rich source of ultra-violet light over the region, which is of great therapeutic use. In medical work, however, the cleanliness and convenience of the method by which any particular radiation can be produced are naturally of great importance, and in this respect it is evident that the electric discharge between a broken column of mercury enclosed in an exhausted quartz tube has much to recommend it. On the other hand, the new tungsten arc lamp made by Messrs. Edison and Swan (see NATure of December 23 , 1915, p. 467), enclosed in a silica bulb instead of in glass, would no doubt be an ideal means of producing ultra-violet light, and one which could be readily adapted for medical as well as other purposes.

Dr. Russ has contributed a short illustrated article to the British Medical Journal for January 22, in which some interesting points are considered respecting the seventeen octaves of radiations which are now available: from visible light to the gamma rays of radium. He deals very clearly with the $\mathrm{X}$-ray spectrum, the dangers of prolonged or frequent exposure to that radiation, ultra-violet light, and some of the chief physical facts with which medical students should become acquainted.

\section{THE UTILISATION OF PEAT.1}

\section{Peat as a Source of Power.}

THE problem of the utilisation of peat for industrial purposes is one of perpetually recurring interest, and scientific men in many countries have turned their attention to search out a solution. This is not surprising in view of the fact that the amount of combustible matter in the world's peat deposits exceeds that of all the known coal-fields. For Ireland the question is one of vital interest. Her coal deposits are small and relatively unimportant, while nearly one-seventh of the area of the country, i.e. more than two and three-quarter million acres, is covered with peat, much of which is of excellent quality. This represents a vast amount of potential energy awaiting oniy a practical means of utilising it.

I Abridged from articles entitled "Peat as a Source of Power," by Mr. Feorge Fletch. $r$, and "Some Chemical A-pects of the Peat Problem," by Agriculture and Technical Instruction for Ireland (vol. xvi., No. I).

No. 24I8, VOL. 97] 